\title{
Aclaración sobre educación digital en el pregrado de medicina
}

\author{
Clarification about digital education in undergraduate medical education
}

\section{Señor Editor:}

Tras leer con interés la carta al editor de GonzalesMendieta et al. (1), sobre algunas herramientas tecnológicas utilizadas en los años de pregrado de la carrera de medicina de la Universidad Peruana Cayetano Heredia (UPCH) a propósito de la cuarentena por la pandemia de la COVID-19, existen algunos aspectos que son importantes precisar.

Desde hace más de diez años, las aulas virtuales de la UPCH se alojan en el Entorno Virtual de Aprendizaje (2), el cual se basa en la conocida plataforma de código abierto Moodle (Moodle Pty Ltd, Perth, Australia). Contrario a lo afirmado por los autores de la carta, este sistema de gestión de aprendizaje tiene entre sus funciones sincrónicas (o en tiempo real) la actividad de "chat" para mensajería instantánea ${ }^{(3)}$. Los foros tienen un propósito diferente; se reservan para la discusión de un tema en particular de forma asincrónica (o en tiempo diferido). Por lo tanto, seria inadecuado postular como limitación la imposibilidad de una interacción sincrónica en los foros.

En cuanto a la posible saturación del servidor que impactaría negativamente en el desarrollo de las evaluaciones en línea, existen otros aspectos tecnológicos inherentes a la institución y a los usuarios que deben también tenerse en cuenta, como por ejemplo la velocidad de conexión. La propuesta de tener otro servidor exclusivo para evaluaciones no sería suficiente debido a que es más importante garantizar un mayor número de conexiones simultáneas.

Respecto a las clases virtuales en tiempo real a través de Zoom (Zoom Video Productions Inc, San José, California, Estados Unidos), los autores hacen uso incorrecto de la palabra "interactividad" al plantearla como característica de la modalidad presencial que no puede ser reemplazable. La interactividad se refiere a las relaciones de una persona ya sea con otra, un recurso o un contenido por medio de las tecnologías de información y comunicaciones (4). Ya que el texto apunta a la relación entre docente y estudiante, lo que corresponde es el término "interacción". Entonces, habría que comparar si la interacción tradicional que ocurre en el salón de clases es similar por videoconferencia. Precisamente, el empleo de una metodología dinámica por el docente para el desarrollo de una clase sería mucho más importarte para los estudiantes en lugar de considerar si la modalidad fuese presencial o virtual ${ }^{(5)}$.

Sobre el software Safe Exam Browser (TH Zurich, Zurich, Suiza), su uso está orientado dentro del campus educativo ya que su única función es inhabilitar cualquier acción ajena a la evaluación y exige la presencia de supervisores y personal técnico. Extenderlo fuera de los ambientes universitarios no sería recomendable por ser un aplicativo de escritorio que requerirá ajustarse a los equipos de los estudiantes (cuyas características son diversas) y la posibilidad que surjan problemas que no puedan ser resueltos de manera remota. Además, los autores señalan utilizarlo junto con Zoom para la supervisión. Sin embargo, Zoom no está diseñado para ello al no contar con herramientas que asistan al supervisor. Mas aún, para que un docente se encargue de una supervisión remota exige de un entrenamiento previo. En cambio, ya existen soluciones por aplicativos web para la supervisión remota de exámenes que registran todas las acciones del evaluado, grabación de pantalla, audio y video para ser revisados posteriormente inclusive con la ayuda de la inteligencia artificial ${ }^{(6)}$ and AIbased proctoring systems (henceforth called as AIPS.

Por último, los autores se equivocan al indicar como propósito del cuestionario de Wong et al., la 
evaluación de percepciones de docentes y alumnos sobre las herramientas tecnológicas en uso; más bien, se trata de una guía de preguntas resultantes de una revisión realista y que serviría de complemento a los criterios en consideración ya sea para el diseño de cursos en línea o en la elección de alguno de estos ${ }^{(7)}$.

\section{Carlos Orellano ${ }^{1, a}$}

\section{Correspondencia:}

Carlos Orellano

Av. Honorio Delgado 430. Urb. Ingeniería. San Martin de Porres.

Lima 15102. Perú.

Correo electrónico: carlos.orellano@upch.pe

\section{REFERENCIAS BIBLIOGRÁFICAS}

1. Gonzales-Mendieta JJ, Váscones-Román FF, Ticse R. Plataformas virtuales en la educación médica de pregrado durante la cuarentena por COVID-19: Una perspectiva estudiantil. Rev Med Hered. 2021; 31(4):290-2.

2. Orellano C. Uso de los espacios virtuales para la docencia en cursos de pregrado de Medicina. Rev Med Hered. 2012; 23(3):188-92.
3. Moodle. Chat activity - MoodleDocs. Perth, Australia: Moodle Pty Ltd; 2020. (Citado el 5 de octubre de 2021). Disponible en: https://docs. moodle.org/311/en/Chat_activity

4. Rodríguez AM, Sosa EA. Interactividad e interacción social: procesos esenciales en educación a distancia. Rev virtual univ catol norte. 2018; 55:110-27.

5. Orellano C, Carcamo C. Evaluating learning of medical students through recorded lectures in clinical courses. Heliyon. 2021; 7(7): e07473. doi: 10.1016/j.heliyon. 2021.e07473

6. Nigam A, Pasricha R, Singh T, Churi P. A Systematic Review on AI-based Proctoring Systems: Past, Present and Future. Educ Inf Technol (Dordr). 2021;1: 1-25. doi: 10.1007/ s10639-021-10597-x

7. Wong G, Greenhalgh T, Pawson R. Internet-based medical education: a realist review of what works, for whom and in what circumstances. BMC Med Educ. 2010; 10:12. doi: 10.1186/1472-6920-10-12

Recibido: 05/10/2021 Aceptado: 07/10/2021

Facultad de Medicina Alberto Hurtado, Universidad Peruana Cayetano Heredia. Lima, Perú.

Médico psiquiatra; Magister en Informática Biomédica. 